Research Paper

\title{
Pioglitazone Use and Risk of Bladder Cancer: an In Vitro Study
}

\author{
Shao-ling Yang ${ }^{1,2^{*}}$, Ji-jiao Wang ${ }^{1,3^{*}}$, Ming Chen ${ }^{1,4}$, Lu Xu${ }^{1}$, Nan Li ${ }^{1}$, Yi-li Luo ${ }^{1}$, Le Bu ${ }^{1}$, Man-na Zhang ${ }^{1}$, Hong \\ $\mathrm{Li}^{1 凶}, \mathrm{Ben}-\mathrm{li} \mathrm{Su}^{3 凶}$ \\ 1. Department of Endocrinology, Shanghai Tenth People's Hospital, Tongji University School of Medicine, Shanghai, 200072, China; \\ 2. Soochow University School of Medicine, Suzhou, 215000, China; \\ 3. Department of Endocrinology, The Second Affiliated Hospital of Dalian Medical University, Dalian 116023, China; \\ 4. Nanjing Medical University, Nanjing, 210000, China; \\ ${ }^{*}$ Contributed equally \\ $\triangle$ Corresponding authors: Hong Li, MD, PhD. Department of Endocrinology, Shanghai Tenth People's Hospital, Tongji University School of Medicine, \\ Yanchang Road No. 301, Jingan District, Shanghai 200072, China. E-mail address: lihong_endo@tongji.edu.cn. and Benli Su, PhD, Msc. Department of \\ Endocrinology, the Second Hospital of Dalian Medical University, Dalian, Liaoning, 116023, China. Email:dlbenlisu@163.com. \\ (C) Ivyspring International Publisher. This is an open access article distributed under the terms of the Creative Commons Attribution (CC BY-NC) license \\ (https://creativecommons.org/licenses/by-nc/4.0/). See http://ivyspring.com/terms for full terms and conditions.
}

Received: 2017.08.16; Accepted: 2017.11.29; Published: 2018.01.08

\begin{abstract}
Aims: Whether pioglitazone (PIO), a peroxisome proliferator-activated receptor-gamma agonist, increases the risk of developing bladder cancer has been debated for several years. The aim of this study was to investigate the in vitro effects of PIO on normal urothelial transitional epithelium (NUTE) cells and bladder cancer (182) cells to further evaluate the risk.

Methods: NUTE cells were obtained from Sprague-Dawley rats. NUTE and 182 cells were treated with different concentrations of PIO for various time periods. Cell proliferation was tested by the MTT assay. Cell apoptosis was evaluated by flow cytometry. The expressions of p53, cyclin D1, $\mathrm{Bcl}-2$, and Bax were determined by qRT-PCR and western blots.

Results: After 24 hours, the treatment of NUTE cells with $10 \mu \mathrm{mol} / \mathrm{L}$ PIO led to morphological changes, without changes in $\mathrm{J} 82$ cells. Moreover, PIO inhibited the proliferation and induced apoptosis of NUTE cells, but not $\int 82$ cells, in a time- and dose-dependent manner. However, PIO did not alter the growth of cells from other tissues. In addition, treatment with PIO for up to 72 hours did not result in changes in the expressions of p53, cyclin DI, Bcl-2, and Bax in NUTE cells and 182 cells. Interestingly, PIO significantly downregulated the protein levels of p53 and cyclin D1 in J82 cells, but not NUTE cells after more than 192 hours of treatment.

Conclusions: PIO did not promote malignant alterations of NUTE cells or stimulate proliferation of 182 cells. PIO decreased the expression of $\mathrm{p} 53$ and cyclin D1 in $\mathrm{J} 82$ cells after long-term culture, which suggested that PIO may be helpful for diabetic patients with bladder cancer.
\end{abstract}

Key words: PPAR gamma; pioglitazone; bladder cancer

\section{Introduction}

Pioglitazone (PIO), an oral antidiabetic agent in the thiazolidinediones (TZD) family, has been widely used in the treatment of type 2 diabetes mellitus since 1999. It acts as an agonist to peroxisome proliferatoractivated receptor-gamma (PPAR- $\gamma$ ), which is a ligand-activated transcription factor of the nuclear hormone receptor superfamily. In addition to its role in the regulation of metabolism and inflammation,
PPARY has also been implicated in carcinogenesis, cellular differentiation, proliferation, and apoptosis [1].

When PIO was first approved in the USA, a preclinical study [2] showed the occurrence of bladder cancer in male rats after PIO treatment, and early clinical studies including the prospective PROspective PioglitAzone Clinical Trial In MacroVascular Events 
Outcome clinical trial (PROactive, 2005) showed a possible safety risk in humans [3-6]. Moreover, meta-analyses in 2014 found that the increased incidence of bladder cancer in PIO users was associated with duration and accumulated dosage [7-10]. However, the latest update of the PROactive study [11], and the Kaiser Permanente Northern California Study (KPNC) [12] with a 10-year follow-up did not show an association between PIO and increased bladder cancer. The findings of these two trials were subsequently corroborated in some observational studies. In the past 2 years, there is growing evidence from clinical studies showing that exposure to PIO is not associated with an increased risk of bladder cancer [13-18].

Along with the debate on whether PIO causes bladder cancer in humans, animal and in vitro cell culture studies have suggested a biological effect of PIO on the induction or protection from bladder cancer [7]. Several in vitro studies also indicated that PIO had antitumor effects. PPARY is expressed in the normal urothelium of all mammalian species but is downregulated in urothelial malignancy [19-21]. PIO was found to suppress the growth of both normal and neoplastic urothelial cells in a dose-dependent manner with normal urothelial cells being more sensitive to PIO than neoplastic cells [22]. However, the mechanism of this inhibitory effect was proposed to be PPAR $\gamma$-independent [23]. Moreover, PPARY promoted urothelial differentiation specifically by inducing the expression of genes associated with late/terminal cytodifferentiation, including cytokeratins, CK13 and CK20, tight junctionassociated claudin3, and uroplakins, UPK1a and UPK2 [24]. Therefore, the effects of PIO on the proliferation and differentiation of urothelial and neoplastic cells remain to be determined.

In this study, we determined the effects of PIO on normal rat urothelial transitional epithelium cells and human bladder cancer J82 cells to ascertain whether PIO promoted neoplastic changes of NUTE cells and proliferation of bladder cancer cells.

\section{Materials and Methods}

\section{Drugs}

PIO (purity, > $99 \%$ ) was purchased from Sigma-Aldrich (St. Louis, MO, USA) and stored in the dark at $-4^{\circ} \mathrm{C}$. A stock solution of PIO was prepared by dissolving it in dimethyl sulfoxide (DMSO; SigmaAldrich). Working solutions of PIO (0, 5, 10, 20 and 40 $\mu \mathrm{mol} / \mathrm{L})$ were prepared by diluting the stock solution in medium. The DMSO concentration in the working solutions was $<0.1 \%$. The same concentration of DMSO $(<0.1 \%)$ was used in the control group.

\section{Cell culture}

Male Sprague Dawley (SD) rats, 8-10 weeks of age, with a mean weight of 180-200 g were purchased from Research Institute of Experimental Animals, Chinese Academy of Medical Science (Shanghai, China). Normal urothelial transitional epithelium (NUTE) cells from the bladder of SD rats were obtained and cultured as described [25]. Briefly, the normal urothelial transitional epithelium tissues were rinsed twice with phosphate-buffered saline (PBS) and cut into 1-5 $\mathrm{mm}^{3}$ pieces. The tissues were then placed into $250 \mathrm{~mL}$ flasks containing $30 \mathrm{~mL}$ of collagenase IV (Sigma-Aldrich) in DMEM/F-12 (Life Technologies, Carlsbad, CA, USA), and incubated on a magnetic stirring apparatus at $37^{\circ} \mathrm{C}$ for $40 \mathrm{~min}$. The NUTE cells were filtered through a $7.5 \times 10^{-2} \mathrm{~mm}$ nylon mesh to generate a single cell suspension. The NUTE cells were established and maintained in DMEM/F12 medium supplemented with 20\% fetal bovine serum (FBS) (Gibco, Carlsbad, CA, USA), containing bovine pituitary extract and epidermal growth factor (EGF) at the manufacturer's recommended concentrations (Hyclone, Logan, UT, USA) and $30 \mathrm{ng} / \mathrm{mL}$ cholera toxin (Sigma-Aldrich). Urothelial carcinoma J82 cells were provided by Shanghai Institutes for Biological Sciences (Shanghai, China) and maintained in DMEM medium supplemented with $10 \%$ FBS at $37^{\circ} \mathrm{C}$ in a humidified atmosphere of $5 \% \mathrm{CO}_{2}$.

\section{Cell proliferation assay}

Both NUTE and J82 cells were treated with different concentrations of PIO $(0,5,10,20$, and 40 $\mu \mathrm{mol} / \mathrm{L})$ for $0,24,48,72$, and $192 \mathrm{~h}$. Cell proliferation was evaluated using 3-(4,5-dimethylthiazol-2-yl)-2,5diphenyltetrazolium bromide (MTT) assays. Briefly, 3 $\times 10^{5}$ cells per well were seeded in 96-well plates, and the cells were exposed to 5, 10, 20, or $40 \mu \mathrm{mol} / \mathrm{L}$ PIO for 24,48 , or 72 h. Equivalent volumes of PBS ( $\mathrm{pH} 7.4$ ) were used as vehicle controls. After treatment, cells were washed with PBS, $100 \mu \mathrm{l}$ of MTT was added, and the cells were incubated at $37^{\circ} \mathrm{C}$ for $4 \mathrm{~h}$. Then, $200 \mu \mathrm{L}$ of DMSO was added, followed by incubation for an additional $30 \mathrm{~min}$ at room temperature in the dark. The optical density was measured with a Bio-Rad Model 3550 Microplate reader (Bio-Rad, Hercules, CA, USA) at $490 \mathrm{~nm}$. The rate of growth inhibition, $(\%)=\left(\mathrm{OD}_{\text {control }}-\mathrm{OD}_{\text {PIO group }}\right) /\left(\mathrm{OD}_{\text {control }}-\mathrm{OD}_{\text {blank group }}\right) \times$ $100 \%$, was calculated.

\section{Cell apoptosis analysis}

After treatment with $0,5,10,20$, and $40 \mu \mathrm{mol} / \mathrm{L}$ PIO for 24, 48, and $72 \mathrm{~h}$, the cells were stained for annexin $\mathrm{V}$ and with propidium iodide (PI) according to the manufacturer's protocol (Becton Dickinson, San 
Jose, CA, USA). Briefly, after drug treatment, $1 \times 10^{5}$ cells were pelleted, washed with PBS, and resuspended in $100 \mu \mathrm{L}$ of binding buffer. Subsequently, cells were incubated with $5 \mu \mathrm{L}$ of annexin V-FITC and PI, followed by incubation for $15 \mathrm{~min}$ at room temperature in the dark. The stained cells were then incubated with $400 \mu \mathrm{L}$ of binding buffer and analyzed by flow cytometry using ModFit software (BD Biosciences, San Diego, CA, USA).

\section{Western blots}

Cells were treated with $10 \mu \mathrm{mol} / \mathrm{L}$ of PIO for 0 , 24, 48, 72, 192, and $240 \mathrm{~h}$, and lysed in RIPA lysis buffer (Sigma-Aldrich), including a cocktail of phosphatase and protease inhibitors (Sigma-Aldrich). Protein concentrations were determined by a bicinchoninic acid (BCA) protein assay. Equal amounts of protein extracts were separated by $10 \%$ sodium dodecyl sulfate-polyacrylamide gel electrophoresis (SDS-PAGE), and transferred onto a nitrocellulose membrane. Membranes were blocked with 5\% (w/v) nonfat dry milk dissolved in Tris-buffered saline plus Tween-20 (TBS-T; 0.1\% Tween-20; $\mathrm{pH}$ 8.3) at room temperature for $1 \mathrm{~h}$, then incubated with primary antibodies at $4^{\circ} \mathrm{C}$ overnight. The primary antibodies used were rabbit anti-p53, anti-cyclin D1, anti-Bcl-2, anti-Bax, and anti- $\beta$-actin (Cell Signaling Technology, Danvers, MA, USA ). The blots were then washed three times with $1 \%$ nonfat dry milk in TBST, and incubated with the corresponding horseradish peroxidase conjugated secondary antibody. The bands were detected using the Pierce enhanced chemiluminescence western blotting substrate (Thermo Scientific, Rockford, IL, USA).

\section{RNA Isolation and quantitative real-time polymerase chain reaction (qRT-PCR)}

Total RNA was extracted from the cells using Trizol $^{\circledR}$ reagent (Invitrogen, Carlsbad, CA, USA) according to the protocol provided by the manufacturer. The synthesis of cDNA was performed using a PrimeScript RT reagent kit (TaKaRa Biotechnology, Dalian, China). Primers for PCR were from PrimerBank (Sangon Biotech, Shanghai, China) and are shown in Table 1 . $\beta$-actin was used as an internal control. The reactions were started at $95^{\circ} \mathrm{C}$ for $10 \mathrm{~s}$, followed by 40 cycles of $95^{\circ} \mathrm{C}$ for $10 \mathrm{~s}$, and $60^{\circ} \mathrm{C}$ for $35 \mathrm{~s}$. The cycle numbers crossing an arbitrary threshold $(\mathrm{Ct})$ were determined using the Application Binary Interface (ABI) system software, version 1.0.410 (Foster City, CA, USA). The fold change in the target RNA relative to $\beta$-actin was calculated as follows:

$$
\Delta \Delta C t=\left(C t_{\text {target }}-C_{\beta \text {-actin }}\right)_{\text {control }}-\left(\mathrm{Ct}_{\text {target }}-\mathrm{Ct}_{\beta \text {-actin }}\right)_{\text {PIO group }}
$$

Table 1. The sequences of PCR primers used in this study

\begin{tabular}{lll}
\hline Genus & Gene & Sequence of primers (5'-3') \\
\hline Human & GAPDH & F:agaaggctggggctcatttg \\
& R:aggggccatccacagtcttc \\
& Cyclin D1 & F:tctacaccgacaactccatcc \\
& R:gtgtttgcggatgatctgttt \\
& p53 & F:ctcctcagcattttatccgagt \\
& R:gctgttccgtccagtagatta \\
& Bcl-2 & F:gaggccaaatatcattctgagg \\
& R:cagtaggtcgggtgagaatagg \\
& Bax & F:aagctgagcgagtgtctcaag \\
& R:caagtagaaagggcgacaac \\
Rat & F:atggtgaaggtcggagtgaac \\
& R:gggtggaatcatactggaacat \\
& Cyclin D1 & F:cacagtatcccagcaaatctt \\
& R:tacaaggcagaagcagcaagta \\
& p53 & F:accaccatccactacaacttca \\
& R:cacaaacacgcacctcaaag \\
& Bcl-2 & F:atgcctttgtggaactgtacg \\
& R:acttcacttgtggcccagata \\
& Bax & F:aagctgagcgagtgtctcaag \\
& R:caaagtagaaagggcgacaac \\
\hline
\end{tabular}

\section{Ethics Statement}

All the SD rat procedures were approved by the Animal Care and Use Committee of The Tenth People's Hospital of Shanghai with permit number 2011-RES1. This study was also approved by the Science and Technology Commission of Shanghai Municipality (ID: SYXK 2007-0006). The SD rats were kept at $18^{\circ} \mathrm{C}-26^{\circ} \mathrm{C}$ on a $12 \mathrm{~h}$ light and dark cycle with free access to water and standard mice chow. All surgery was performed under sodium pentobarbital anesthesia, and every effort was made to minimize suffering.

\section{Statistical analysis}

All data represent the mean \pm SD (standard deviation). Student's $t$-tests were performed to evaluate the differences between treated groups and their paired controls. A $\mathrm{P}$ value $<0.05$ was considered statistically significant (denoted by aP $<0.05$, bP $>$ 0.05). The analyses were conducted with Image J software (NIH, Bethesda, MD, USA), GraphPad Prism 5.0 software (San Diego, CA, USA), and SPSS, version 17 (SPSS, Chicago, IL, USA).

\section{Results}

\section{PIO treatment results in morphological changes in NUTE and $\mathbf{~} 82$ cells}

The NUTE cells grew as monolayers with typical epithelioid cobblestone morphology. Compared with that of the control group, $10 \mu \mathrm{mol} / \mathrm{L}$ PIO treatment for $24 \mathrm{~h}$ resulted in apparent morphological alterations of NUTE cells as observed under light microscopy (Figure 1A and B). This inhibitory effect was enhanced with the prolongation of treatment time and increased PIO concentrations. For example, $10 \mu \mathrm{mol} / \mathrm{L}$ of PIO treatment for more than $72 \mathrm{~h}$ led to 
extensive cytoplasmic blebbing and nuclear fragmentation of NUTE cells (Figure 1B). PIO treatment resulted in only negligible cell morphological changes of J82 cells with increased PIO concentrations and treatment times (Figure 1C and D), and J82 cells only became mildly tear-shaped following treatment with $10 \mu \mathrm{mol} / \mathrm{L}$ of PIO for more than $72 \mathrm{~h}$ (Figure 1D). In contrast, liver cells, kidney cells, and vascular endothelial cells (data not shown) from normal SD rats did not show any changes in morphology following treatments with $10 \mu \mathrm{mol} / \mathrm{L}$ of PIO for $72 \mathrm{~h}$ (Figure 2). These results indicated that PIO treatment led to obvious morphological changes of normal urothelial transitional epithelium cells in vitro.

\section{Effects of PIO on cells proliferation}

To assess the effects of PIO on the proliferation of NUTE and J82 cells, we treated NUTE and J82 cells with $0,5,10,20$, or $40 \mu \mathrm{mol} / \mathrm{L}$ PIO for $0,24,48$, and 72 h. Cell proliferation was evaluated by MTT assays. We found that either low (5-10 $\mu \mathrm{mol} / \mathrm{L})$ or high (20-40 $\mu \mathrm{mol} / \mathrm{L})$ concentrations of PIO had no significant effect on the proliferation of J82 cells ( $\mathrm{P}>$ 0.05). However, for NUTE cells, $10 \mu \mathrm{mol} / \mathrm{L}$ of PIO significantly inhibited the proliferation after $24 \mathrm{~h}$ when compared with that of the control group (Figure 3). Moreover, greater inhibitory effects were observed when the cells were treated for $48 \mathrm{~h}$ and $72 \mathrm{~h}$, or with $20 \mu \mathrm{mol} / \mathrm{L}$ of PIO $(\mathrm{P}<0.05$, Figure 3). Thus, PIO

inhibited the proliferation of NUTE cells in a timeand dose-dependent manner.

\section{PIO induces apoptosis of NUTE but not J82 cells}

To test whether PIO induced apoptosis, we treated NUTE and J82 cells with $10 \mu \mathrm{mol} / \mathrm{L}$ of PIO for $24 \mathrm{~h}$ and $72 \mathrm{~h}$, and analyzed cell apoptosis by annexin $\mathrm{V}$ and PI staining coupled with flow cytometry analyses. There were no significant differences of the percentage of J82 cells undergoing apoptosis between the treated groups and the control group. After treatment with $10 \mu \mathrm{mol} / \mathrm{L}$ of PIO for $48 \mathrm{~h}$, the percentages of surviving J82 cells with annexin-V-FITC staining for the PIO group and control group were $6.3 \pm 1.5 \%$ and $6.9 \pm 1.6 \%$, respectively. In addition, the proportions of surviving J82 cells with annexin-V-FITC staining after treatment with $10 \mu \mathrm{mol} / \mathrm{L}$ of PIO for 24 and $72 \mathrm{~h}$ were $7.5 \pm 1.6 \%$ and $7.7 \pm 1.9$, respectively. In contrast, $10 \mu \mathrm{mol} / \mathrm{L} \mathrm{PIO}$ treatment for $24 \mathrm{~h}$ significantly increased cell apoptosis of NUTE cells $(18.8 \pm 2.1 \%)$ in comparison to that of control cells $(9.4 \pm 1.7 \%)(\mathrm{P}<0.05)$ (Figure $4 \mathrm{~A}$ and $\mathrm{B})$. The percentage of apoptotic cells treated with $10 \mu \mathrm{mol} / \mathrm{L}$ of PIO for $72 \mathrm{~h}$ was $49.7 \pm 2.3 \%$, while that of the control cells was $11.3 \pm 1.3 \%(\mathrm{P}<0.05)$ (Figure 4A and B). These results showed that PIO dose-dependently induced apoptosis of NUTE cells.

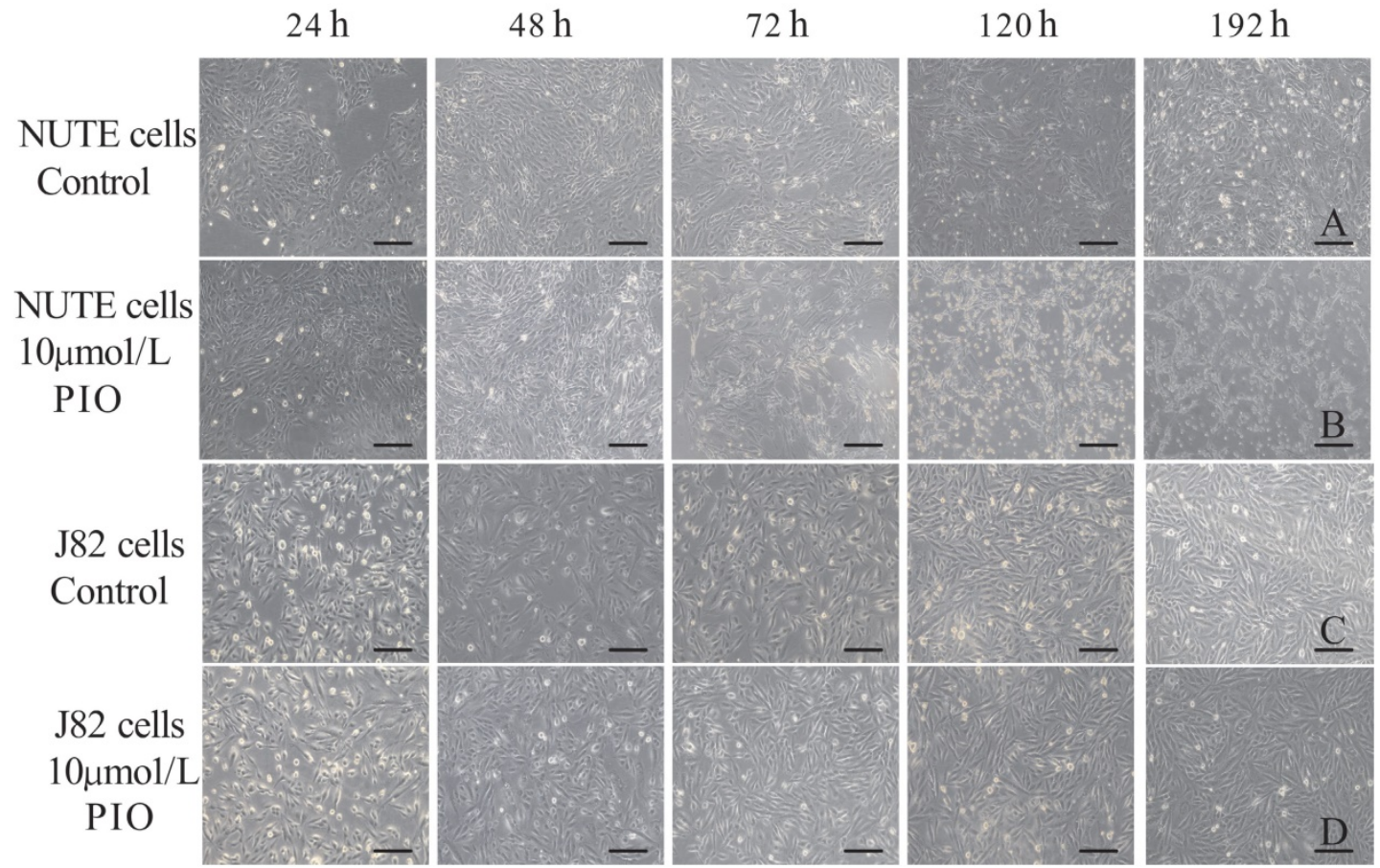

Figure 1. Pioglitazone (PIO) treatment resulted in morphological changes of NUTE and J82 cells. A: NUTE cells were cultured in the absence of PIO for the indicated times, and cell morphology was observed under a light microscope. B: NUTE cells were treated with $10 \mu \mathrm{mol} / \mathrm{L}$ PIO for the indicated times, and cell morphology was observed under a light microscope. C: $\mathrm{J} 82$ cells were cultured in the absence of PIO for the indicated times, and cell morphology was observed under a light microscope. D: $\mathbf{3} 82$ cells were treated with $10 \mu \mathrm{mol} / \mathrm{L}$ PIO for the indicated times, and cell morphology was observed under a light microscope. Scale bars: 200 $\mu \mathrm{m}$. 


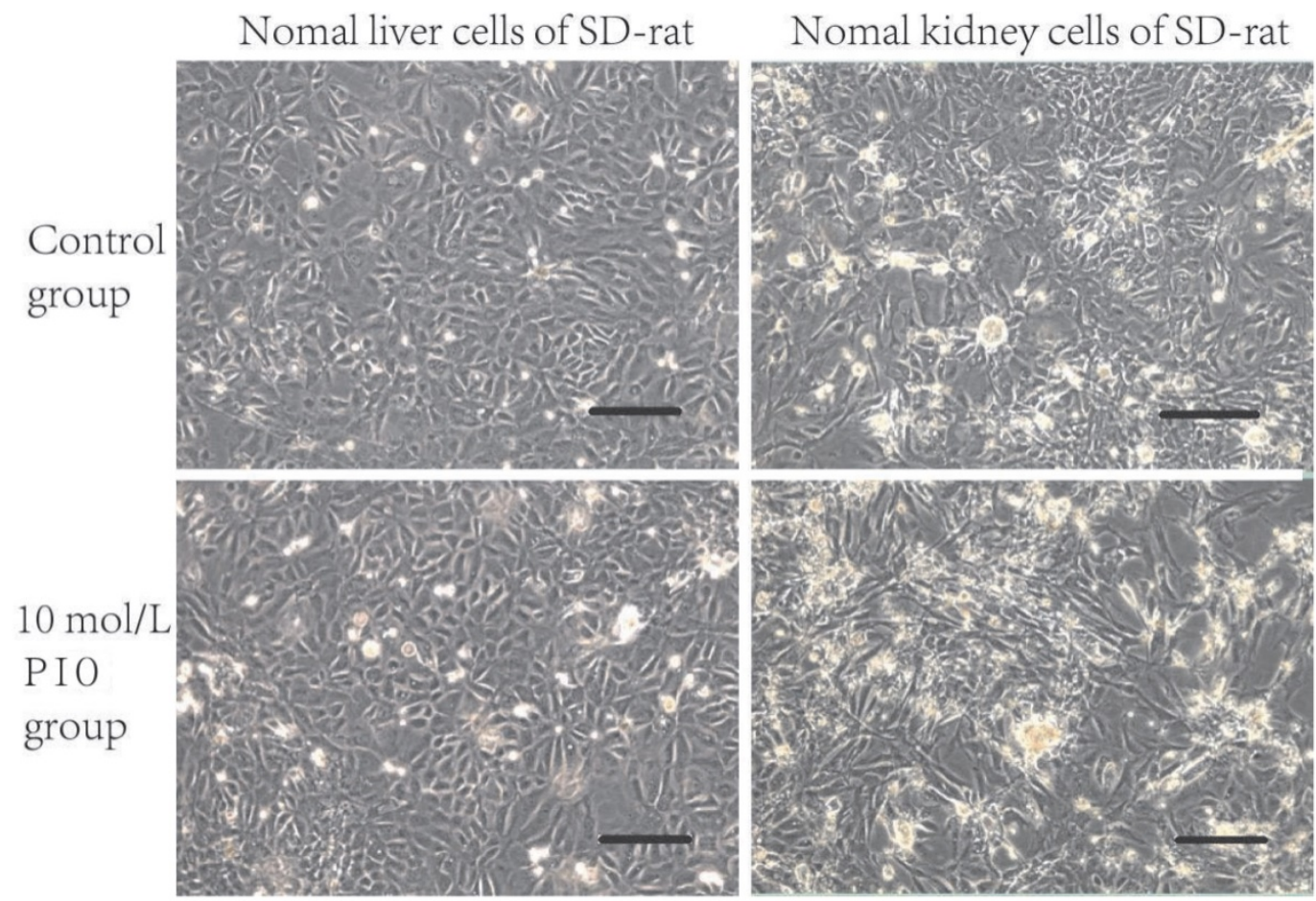

Figure 2. Pioglitazone (PIO) treatment did not alter the morphology of the liver cells and kidney cells from normal Sprague Dawley (SD) rats. Liver cells and kidney cells from normal SD rats were treated with $10 \mu \mathrm{mol} / \mathrm{L}$ of PIO for $72 \mathrm{~h}$. Cell morphology was observed under a light microscope. Scale bars: $200 \mu \mathrm{m}$.

\section{PIO downregulates the protein levels of p53 and cyclin D1 after long-term treatment in $\mathbf{} 82$ cells.}

We measured the expressions of p53, cyclin D1, Bcl-2, and Bax by qRT-PCR and western blotting, respectively. The qRT-PCR results showed that the mRNA levels of p53, cyclin D1, Bcl-2, and Bax displayed little change both in the NUTE cells and the J82 cells following treatments with 5, 10, 20, and 40 $\mu \mathrm{mol} / \mathrm{L}$ of PIO for 24, 48, and $72 \mathrm{~h}$ (data not shown). Similarly, PIO did not significantly alter the protein levels of p53, cyclin D1, Bcl-2, and Bax in NUTE cells treated with $10 \mu \mathrm{mol} / \mathrm{L}$ of PIO for 24, 48 and $72 \mathrm{~h}$ (Figure 5). In J82 cells, PIO did not change the protein levels of Bcl-2 and Bax after treatment with $10 \mu \mathrm{mol} / \mathrm{L}$ of PIO for 24, 48, and $72 \mathrm{~h}$ (Figure 5A, D, and E). Interestingly, PIO decreased the protein levels of p53 and cyclin D1 in J82 cells after treatment with 10 $\mu \mathrm{mol} / \mathrm{L}$ of PIO for $192 \mathrm{hr}$ (Figure 5A, B, and C).

\section{Discussion}

PPAR- $\gamma$ a member of the nuclear receptor superfamily, and takes part in the regulation of adipogenesis and insulin sensitivity. A wide range of synthetic PPAR- $\gamma$ ligands have been identified and several, such as PIO, are clinically used as anti-diabetic agents. Since the adoption of PIO, its use has been questioned due to concerns about the potential risk of bladder cancer. There are currently two main views regarding PIO in bladder cancer risk. First, PIO can lead to an increased risk of bladder cancer. Several studies showed an increased risk of bladder cancer in diabetic patients using PIO, especially for men with long-term and high dose exposures [16, 26-27]. Data from the U.S. Food and Drug Administration (FDA) Adverse Event Reporting System (AERS) between 2004 and 2009 indicated a definite risk from PIO [hazard ratio (HR), 4.30; 95\% confidence interval (CI), 2.82-6.52] [28]. A French observational retrospective cohort study of 1,491,060 patients also found a moderate but significantly increased risk of bladder cancer among PIO users (HR, 1.22; 95\% CI, 1.05-1.43; P = 0.01) [29]. In further support of this view, it was reported that PIO in rats induced bladder tumors related to the formation of urinary solids, which were cytotoxic to the urothelium, resulting in regenerative proliferation and ultimately tumors $[2,30]$. However, the opposite opinion is that PIO usage does not increase the risk of bladder cancer. Levin et al. [31] reported that among 1.01 million cases from six populations across the world, there was no evidence for any association between cumulative exposure to PIO and bladder cancer in males (RR, 1.01; 95\% CI, 0.97-1.06) or females [relative risk (RR) 1.04; 95\% CI, 0.97-1.11], after adjustment for age, calendar year, diabetes duration, smoking status, and any previous use of 
PIO. Moreover, Chedgy et al. [32], reported that in 193,099 diabetic patients aged $\geq 40$ years, $18 \%(34,181)$ of the patients in the bladder cancer cohort had received PIO for a median duration of 2.8 years. During the observation period, a new bladder tumor was diagnosed in 1,261 (0.65\%) patients. Further analyses indicated that no association was found between PIO use and risk of bladder cancer (HR, 1.06; 95\% CI, 0. 89-1.26). In addition, no association was observed with time since initiation, duration of PIO use, and increasing PIO dose. Furthermore, Pasi et al. [33] found that in patients with type 2 diabetes who initiated PIO use ( $\mathrm{n}=56,337)$, matched with patients with type 2 diabetes in the same country exposed to diabetes drug treatments other than PIO $(n=317,109)$, with regards to risk of bladder cancer, the adjusted HR for patients exposed versus never exposed to PIO was 0.99 (95\% CI, 0.75-1.30). The results showed no evidence of an association between those having used PIO and risk of bladder cancer, compared with those never using PIO. The recent meta-analyses also showed there was no association of PIO use with bladder cancer occurrence [15]. Data from some animal studies also supported this finding [34].
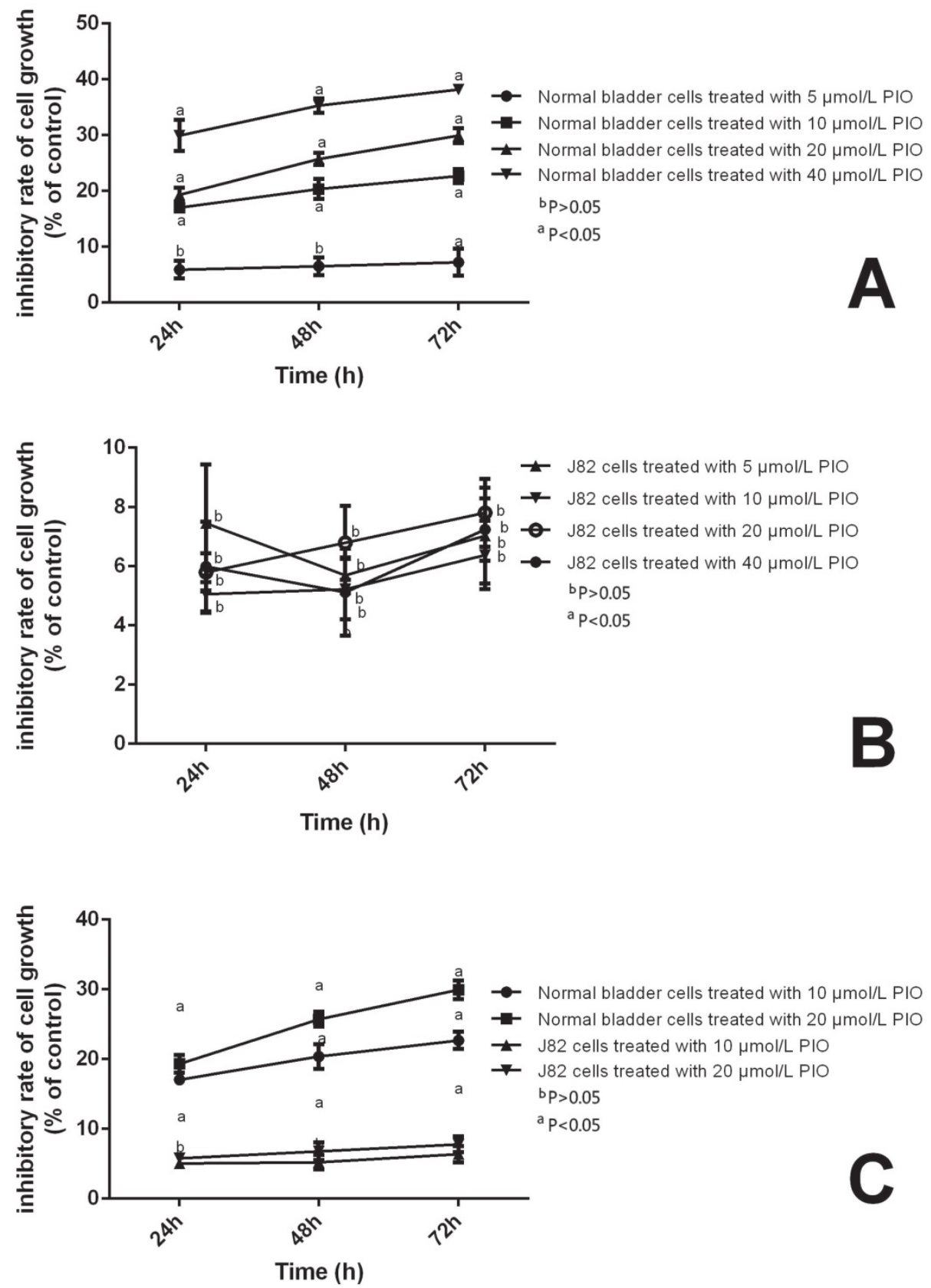

Figure 3. Pioglitazone (PIO) inhibited the proliferation of NUTE cells but not $J 82$ cells. NUTE and $\mathrm{J} 82$ cells were treated with 0,10 , or $20 \mu \mathrm{mol} / \mathrm{L}$ PIO for $0,24,48$, and $72 \mathrm{~h}$. Cell proliferation was evaluated by the 3-(4,5-dimethylthiazol-2-yl)-2,5-diphenyltetrazolium bromide (MTT) assay. 

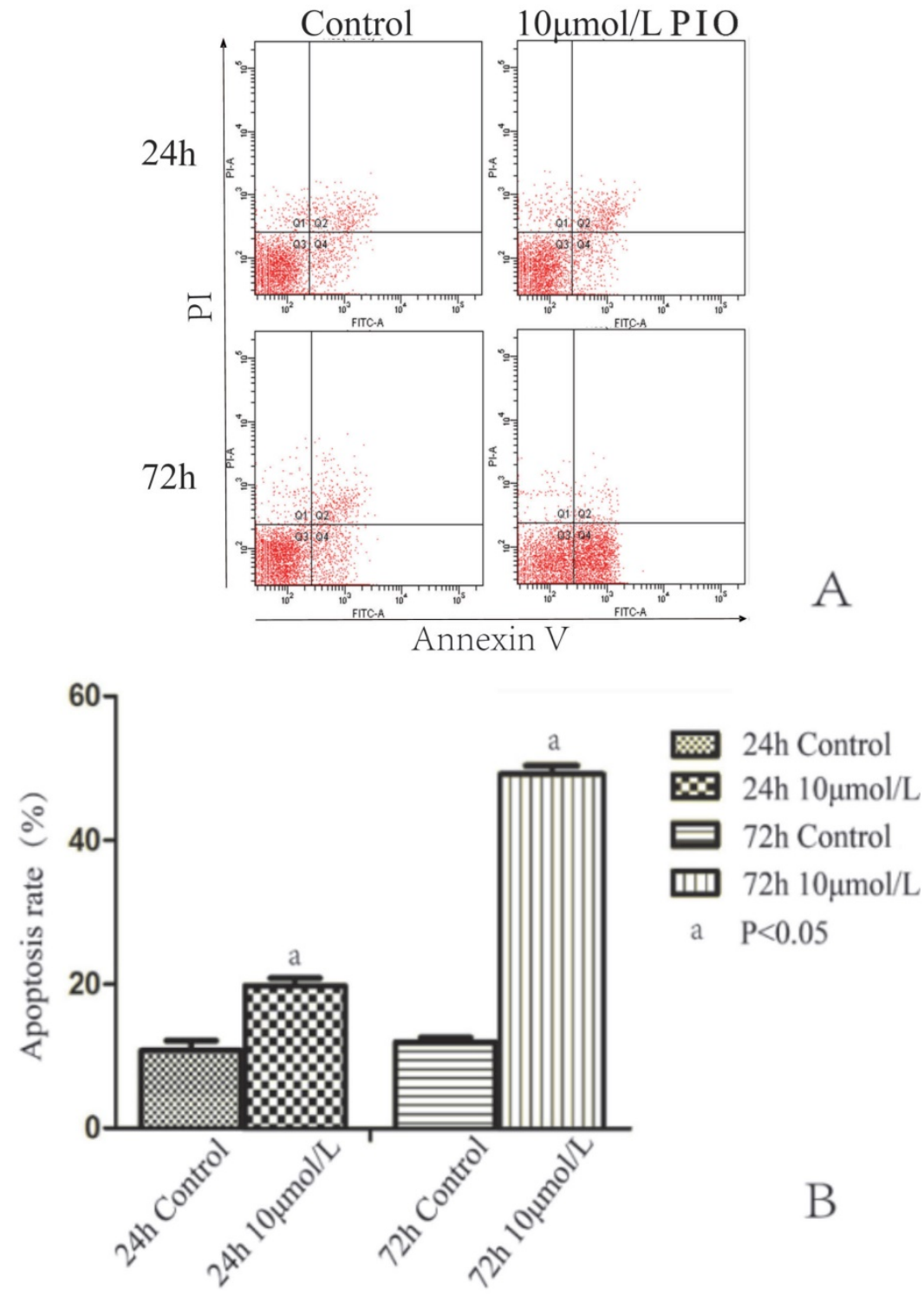

Figure 4. Pioglitazone (PIO) induced apoptosis of NUTE cells but not $J 82$ cells. A. 882 cells were treated with $10 \mu$ mol/L or without PIO for 24 and $72 \mathrm{~h}$, and cell apoptosis was analyzed by annexin $\mathrm{V}$ and propidium iodide $(\mathrm{PI})$ staining coupled with flow cytometry analyses. A representative flow cytometry scan is shown. Q1: late stage apoptotic cells; Q2: dead cells; Q3: living cells; Q4: early stage apoptotic cells. Apoptosis rate $(\%)$ of cells $=(Q 1+Q 4) \times 100 \%$. B. Quantitative analyses of apoptosis rate (\%) of NUTE cells treated with $10 \mu \mathrm{mol} / \mathrm{L}$ PIO for $24 \mathrm{~h}$ and $72 \mathrm{~h}$.

The current studies mainly involved epidemiological investigations. Due to the limited number and short time period study in the random control trials, and the inherent limits in observational studies, the association between PIO use and bladder cancer is still controversial [6]. Therefore, both in vitro investigations and animal models are needed to resolve this debate. Here, we have studied the effects of PIO on rat normal urothelial transitional epithelium cells and human bladder cancer J82 cells to explore the association between PIO and bladder cancer from the perspective of basic research.

In this study, we showed that PIO treatment led to morphological changes of normal urothelial transitional epithelium cells (NUTE cells). Moreover, PIO inhibited the proliferation and induced apoptosis of NUTE cells but not J82 cells in a time- and dose-dependent manner. In addition, PIO downregulated the protein levels of p53 and cyclin D1 in J82, but not NUTE cells, after long-term treatment. Our findings suggested that PIO may not elevate the risk of bladder cancer in NUTE cells or promote bladder cancer cell proliferation.

Deregulation of cell proliferation and evasion of apoptosis are two hallmarks of cancer cells. To address the contradictory observations regarding the usage of PIO and the risk of bladder cancer, one critical question is whether PIO can affect the proliferation and apoptosis of bladder cells. In the present study, the NUTE cell viability was significantly decreased after $24 \mathrm{~h}$ when cultured with 10 $\mu \mathrm{mol} / \mathrm{L}$ PIO, and the inhibitory effects were time- and 
dose-dependent. Significant apoptosis was found in NUTE cells treated with $10 \mu \mathrm{mol} / \mathrm{L}$ of PIO. In contrast, cells from other tissues, including liver, kidney, and vascular endothelium, showed no cell death after treatment with PIO $(10 \mu \mathrm{mol} / \mathrm{L})$. This finding was consistent with those from a previous study [35]. These results suggested that PIO had selective toxicity to NUTE cells. These results also corroborated those of our clinical observations, that after taking PIO, several diabetic patients felt bladder discomfort, which may have been related with cellular apoptosis.

The inhibition of bladder cell growth by PIO might be explained by cell cycle arrest, the induction of apoptosis, and/or terminal differentiation [36]. It was proposed that thiazolidinediones, PPARY ligands, could induce tumor cell apoptosis by downregulating Bcl-2 and upregulating Bax [37-38]. Both Bax and Bcl-2 are expressed in the urothelium and play important roles in regulating apoptosis [39]. However, in our study, both western blots and qRT-PCR analyses showed that there were no significant changes in Bcl-2 and Bax expression in NUTE cells when cultured with PIO. Thus, the induction of apoptosis in NUTE cells by PIO was not through the classical Bcl-2 and Bax pathways.

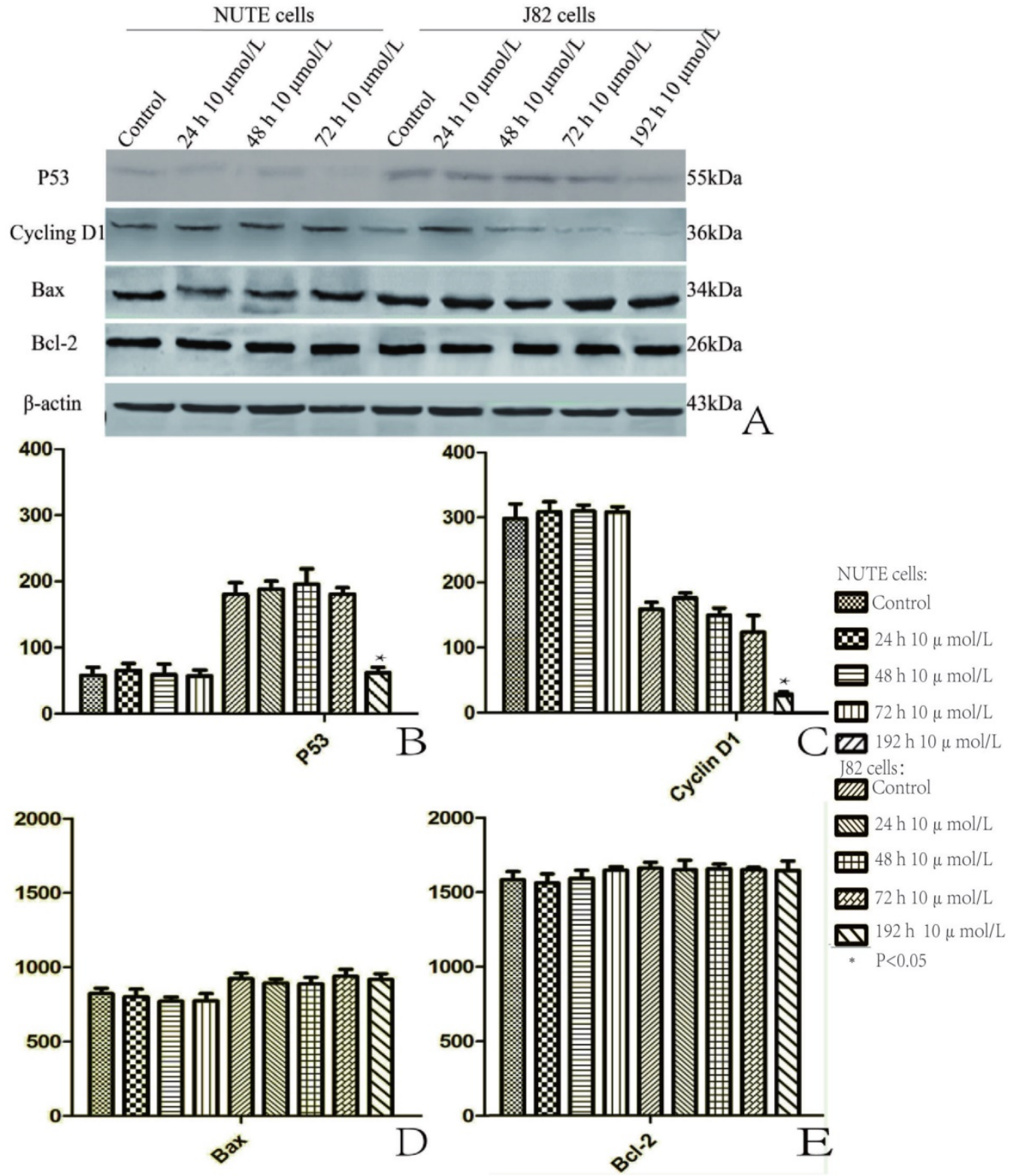

Figure 5. Pioglitazone (PIO) reduced the protein levels of p53 and cyclin DI after long-term treatment of J82 cells. A. NUTE and J82 cells were treated with $10 \mu \mathrm{mol} / \mathrm{L}$ or without PIO for the indicated times. Total protein was extracted for immunoblotting of $\mathrm{p} 53$, cyclin D1, Bcl-2, and Bax, with $\beta$-actin used as a loading control. B. The protein expression of p53 is shown as gray stripes. C. The protein expression of cyclin D1 is shown as gray stripes. D. The protein expression of Bax is shown as gray stripes. $\mathbf{E}$. The protein expression of $\mathrm{Bcl}-2$ is shown as gray stripes.

Enhanced cell proliferation due to loss of cell cycle regulation is one of the most important 
molecular and genetic changes in bladder carcinoma [39]. The occurrence and development of a tumor are under the regulation of multiple oncogenes and tumor suppressor genes. Aberrant expressions of cyclin D1 and cyclin E, downregulations of p16 and p27, and mutations of $\mathrm{Rb}$ and p53 have been frequently observed in several types of cancers [40-42]. The altered expression of cyclin D1 is associated with a risk of bladder cancer. The wild type p53 gene, the most important tumor suppressor gene, prevents tumorigenesis by inhibiting cell proliferation and transformation. The $p 53$ gene is mutated in most cancers and mutant p53 protein promotes malignant transformation. It was found that accumulation of mutant p53 was closely related to the grading of bladder cancer and the progress of tumor proliferation [43]. Generally, mutant p53 is easily detected by its longer half-life than wild type p53 [44]. In our study in NUTE cells and J82 cells treated with $10 \mu \mathrm{mol} / \mathrm{L}$ PIO, there were no significant changes in both cyclin D1 and p53. This may be because PIO treatment in vitro may not promote the malignant alteration of NUTE cells, or accelerate J82 cell proliferation. However, chronic treatment (for $192 \mathrm{~h}$ ) with $10 \mu \mathrm{mol} / \mathrm{L}$ of PIO reduced the expression levels of cyclin D1 and p53 in J82 cells, suggesting that PIO might slow the progress of bladder cancer. Our findings were consistent with a previous conclusion that PIO suppressed the growth of non-neoplastic and neoplastic urothelial cell in a dose-dependent manner [19-20].

In summary, this study supported the following conclusions: 1) PIO usage may not elevate the risk of bladder cancer; 2) PIO might reduce the tumorigenesis of bladder cancer cells after a chronic process; and 3) PIO could exert a tissue-specific apoptosis in NUTE cells. Based on the existing data, we speculated that patients with diabetes treated with PIO may not have an increased risk of bladder cancer, and that PIO use in diabetic patients with diagnosed bladder cancer will not promote tumor progress, but may inhibit tumor development.

\section{Acknowledgments}

This work was supported by grants from the National Natural Science Foundation of China (No. 81500687) and the National Key Research and Development Program of China (2016YFC1305601).

\section{Competing Interests}

The authors have declared that no competing interest exists.

\section{References}

1. Cariou B, Charbonnel B, Staels B. Thiazolidinediones and PPARgamma agonists: time for a reassessment. Trends Endocrinol Metab. 2012; 23(5): 205-15.

2. Cohen SM. Effects of PPARgamma and combined agonists on the urinary tract of rats and other species. Toxicol Sci. 2005; 87(2): 322-7.

3. U.S. Food and Drug Administration. FDA Drug Safety Communication: Update to ongoing safety review of Actos (pioglitazone) and increased risk of bladder cancer. 2011 Safety Announcement. Accessed December 24, 2011. http://www.fda.gov/Drugs/DrugSafety/ucm259150.htm.

4. Oleksiewicz MB, Thorup I, Nielsen HS, et al. Generalized cellular hypertrophy is induced by a dual-acting PPAR agonist in rat urinary bladder urothelium in vivo. Toxicol Pathol. 2005; 33(5): 552-60.

5. Oleksiewicz MB, Southgate J, Iversen L, et al. Rat Urinary Bladder Carcinogenesis by Dual-Acting PPARalpha + gamma Agonists. PPAR Res. 2008; 2008: 103167.

6. Dormandy JA, Charbonnel B, Eckland DJA, et al. Secondary prevention of macrovascular events in patients with type 2 diabetes in the PROactive Study (PROspective pioglitAzone Clinical Trial In macroVascular Events): a randomised controlled trial. The Lancet. 2005; 366(9493): 1279-89.

7. Tseng $\mathrm{CH}$. A review on thiazolidinediones and bladder cancer in human studies. J Environ Sci Health C Environ Carcinog Ecotoxicol Rev. 2014; 32(1): $1-45$.

8. Monami M, Dicembrini I, Mannucci E. Thiazolidinediones and cancer: results of a meta-analysis of randomized clinical trials. Acta Diabetol. 2014; 51(1): 91-101.

9. He S, Tang $\mathrm{YH}$, Zhao G, et al. Pioglitazone prescription increases risk of bladder cancer in patients with type 2 diabetes: an updated meta-analysis. Tumour Biol. 2014; 35(3): 2095-102.

10. Turner RM, Kwok CS, Chen-Turner C, et al. Thiazolidinediones and associated risk of bladder cancer: a systematic review and meta-analysis. Br J Clin Pharmacol. 2014; 78(2): 258-73.

11. Erdmann E, Harding S, Lam H, et al. Ten-year observational follow-up of PROactive: a randomized cardiovascular outcomes trial evaluating pioglitazone in type 2 diabetes. Diabetes Obes Metab. 2016; 18(3): 266-73.

12. Lewis JD, Habel LA, Quesenberry CP, et al. Pioglitazone Use and Risk of Bladder Cancer and Other Common Cancers in Persons With Diabetes. JAMA. 2015; 314(3): 265-77.

13. Balaji $V$, Seshiah $V$, Ashtalakshmi $G$, et al. A retrospective study on finding correlation of pioglitazone and incidences of bladder cancer in the Indian population. Indian J Endocrinol Metab. 2014; 18(3): 425-7.

14. Kuo HW, Tiao MM, Ho SC, et al. Pioglitazone use and the risk of bladder cancer. Kaohsiung J Med Sci. 2014; 30(2): 94-7.

15. Lee MY, Hsiao PJ, Yang YH, et al. The association of pioglitazone and urinary tract disease in type 2 diabetic Taiwanese: bladder cancer and chronic kidney disease. PLoS One. 2014; 9(1): e85479.

16. Jin $\mathrm{SM}$, Song $\mathrm{SO}$, Jung $\mathrm{CH}$, et al. Risk of bladder cancer among patients with diabetes treated with a $15 \mathrm{mg}$ pioglitazone dose in Korea: a multi-center retrospective cohort study. J Korean Med Sci. 2014; 29(2): 238-42.

17. Vallabhajosyula S, Vallabhajosyula S, Vallabhajosyula S, et al. Development of vascular complications and bladder carcinoma in diabetics using pioglitazone: A five-year Indian review. Med J Armed Forces India. 2016; 72(3): 253-7.

18. Gupta S, Gupta K, Ravi R, et al. Pioglitazone and the risk of bladder cancer: An Indian retrospective cohort study. Indian J Endocrinol Metab. 2015; 19(5): 639-43.

19. Guan Y, Zhang $Y$, Davis $L$, et al. Expression of peroxisome proliferator-activated receptors in urinary tract of rabbits and humans. Am J Physiol. 1997; 273: 1013-22.

20. Braissant O, Foufelle F, Scotto C, et al. Differential expression of peroxisome proliferator-activated receptors (PPARs): tissue distribution of PPAR-alpha, -beta, and -gamma in the adult rat. Endocrinology. 1996; 137(1): 354-66.

21. Jain S, Pulikuri S, Zhu Y, et al. Differential Expression of the Peroxisome ProliferatorActivated Receptor gamma (PPAR gamma) and Its Coactivators Steroid Receptor Coactivator-1 and PPAR-Binding Protein PBP in the Brown Fat, Urinary Bladder, Colon, and Breast of the Mouse. Am J Pathol. 1998; 153: 349-54.

22. Nakashiro KI, Hayashi Y, Kita A, et al. Role of peroxisome proliferator-activated receptor gamma and its ligands in non-neoplastic and neoplastic human urothelial cells. Am J Pathol. 2001;159(2):591-7.

23. Chaffer CL, Thomas DM, Thompson EW, et al. PPARgamma-independent induction of growth arrest and apoptosis in prostate and bladder carcinoma. BMC Cancer. 2006;6:53.

24. Varley CL, Southgate J. Effects of PPAR agonists on proliferation and differentiation in human urothelium. Exp Toxicol Pathol. 2008;60(6):435-41.

25. Johnson MD, Bryan GT, Reznikoff CA. Serial cultivation of normal rat bladder epithelial cells in vitro. J Urol. 1985;133(6):1076-81.

26. Lewis JD, Habel L, Quesenberry C, et al. Proteinuria testing among patients with diabetes mellitus is associated with bladder cancer diagnosis: potential for unmeasured confounding in studies of pioglitazone and bladder cancer. Pharmacoepidemiol Drug Saf. 2014;23(6):636-45.

27. Tuccori M, Filion KB, Yin $\mathrm{H}$, et al. Pioglitazone use and risk of bladder cancer: population based cohort study. BMJ. 2016;352:i1541. 
28. Piccinni C, Motola D, Marchesini G, et al. Assessing the association of pioglitazone use and bladder cancer through drug adverse event reporting. Diabetes Care. 2011;34(6):1369-71.

29. Neumann A, Weill A, Ricordeau P, et al. Pioglitazone and risk of bladder cancer among diabetic patients in France: a population-based cohort study. Diabetologia. 2012;55(7):1953-62.

30. Bojkova B, Orendas P, Kubatka P, et al. Positive and negative effects of glitazones in carcinogenesis: experimental models vs. clinical practice. Pathol Res Pract. 2014;210(8):465-72.

31. Levin D, Bell S, Sund R, et al. Pioglitazone and bladder cancer risk: a multipopulation pooled, cumulative exposure analysis. Diabetologia. 2015;58(3):493-504.

32. Chedgy EC, Black PC. Pioglitazone: No Longer a Worry for Bladder Cancer? Urology. 2016;91:19-20.

33. Korhonen P, Heintjes EM, Williams R, et al. Pioglitazone use and risk of bladder cancer in patients with type 2 diabetes: retrospective cohort study using datasets from four European countries. BMJ. 2016;354:i3903.

34. Takashima $T$, Fujiwara $Y$, Hihuchi $K$, et al. PPAR-gamma ligands inhibit growth of human esophageal adenocarcinoma cells through induction of apoptosis, cell cycle arrest and reduction of ornithine decarboxylase activity. Int J Oncol. 2001; 19: 465-71.

35. Li J, Wang H, Ma Z, et al. TAT-Apoptin induces apoptosis in the human bladder cancer EJ cell line and regulates Bax, Bcl-2, caspase- 3 and survivin expression. Exp Ther Med. 2012;3(6):1033-8.

36. Ajili F, Kaabi B, Darouiche A, et al. Prognostic value of Bcl-2 and Bax tumor cell expression in patients with non muscle-invasive bladder cancer receiving bacillus Calmette-Guerin immunotherapy. Ultrastruct Pathol. 2012;36(1):31-9.

37. Plissonnier ML, Fauconnet $\mathrm{S}$, Bittard $\mathrm{H}$, et al. Insights on distinct pathways of thiazolidinediones (PPARgamma ligand)-promoted apoptosis in TRAIL-sensitive or -resistant malignant urothelial cells. Int J Cancer. 2010;127(8):1769-84

38. Williams SG, Stein JP. Molecular pathways in bladder cancer. Urol Res. 2004;32(6):373-85.

39. Lee K, Jung ES, Choi YJ, et al. Expression of pRb, p53, p16 and cyclin D1 and their clinical implications in urothelial carcinoma. J Korean Med Sci. 2010;25(10):1449-55.

40. Yun SJ, Moon SK, Kim WJ. Investigational cell cycle inhibitors in clinical trials for bladder cancer. Expert Opin Investig Drugs. 2013:22(3):369-77.

41. Li J, Qu W, Cheng Y, et al. The inhibitory effect of intravesical fisetin against bladder cancer by induction of p53 and down-regulation of NF-kappa B pathways in a rat bladder carcinogenesis model. Basic Clin Pharmacol Toxicol. 2014;115(4):321-9.

42. Otsuka J, Okuda T, Sekizawa A, et al. Detection of p53 mutations in the plasma DNA of patients with ovarian cancer. Int J Gynecol Cancer. 2004;14(3):459-64.

43. Sturzbecher HW, Chumakov P, Welch WJ, et al. Mutant p53 proteins bind hsp $72 / 73$ cellular heat shock-related proteins in SV40-transformed monkey cells. Oncogene. 1987;1(2):201-11.

44. Young AR, Narita M, Narita M. Cell senescence as both a dynamic and a static phenotype. Methods Mol Biol. 2013;965:1-13. 